\title{
The Optimizing of Counselor Competence for Multicultural Counseling
}

\author{
Yudhi Purwa Nugraha ${ }^{1,3}$, Anastasia Hariyati ${ }^{2,3}$, Fitri Uswatun Khasanah ${ }^{1,3}$ \\ Universitas Sebelas Maret ${ }^{1}$, Universitas Sanata Dharma Yogyakarta ${ }^{2}$, \\ Universitas Negeri Semarang ${ }^{3}$ \\ yudhi.purwa94@gmail.com
}

\section{Article History \\ accepted 01/11/2019}

approved $11 / 11 / 2019$ published 31/12/2019

\begin{abstract}
Indonesia has a variety of cultures. Each culture has special characteristics. Special characteristics of each culture can cause obstacles to the individual. Experiences by students who come from different cultures. Students from different cultures show language barriers, academic barriers, barriers in values and norms, and experience racism. Educators' low multicultural competence also influence it. The objective of this article is to prepare school counselors for provide multicultural services based data needs of students through the exploration of feelings, competencies, enthusiasm, opportunities and goals to develop multicultural service programs in a programmed, systematic, integrated, and sustainable manner, expected to be able to help develop students' competencies optimally. The next objective is to analyze the implementation of multicultural counseling with an eclectic approach based on data exploration of the students' potential. The assistance provided by the counselor is based on techniques Psychodynamic, Existential-Humanistic, Cognitive Behavioral Therapy, Post-Modern approaches.
\end{abstract}

Keywords: Counseling, Multicultural, Eclectic

\begin{abstract}
Abstrak
Indonesia memiliki beragam budaya. Setiap budaya memiliki karakteristik khusus. Karakteristik khusus dari masing-masing budaya dapat menyebabkan hambatan bagi individu. Pengalaman oleh peserta didik yang berasal dari budaya yang berbeda. Peserta didik dari budaya yang berbeda menunjukkan hambatan bahasa, hambatan akademis, hambatan dalam nilai dan norma, dan mengalami rasisme. Kompetensi multikultural yang rendah dari para pendidik juga memengaruhinya. Tujuan dari artikel ini adalah untuk mempersiapkan konselor sekolah untuk menyediakan layanan data berbasis kebutuhan multikultural peserta didik melalui eksplorasi perasaan, kompetensi, antusiasme, peluang dan tujuan untuk mengembangkan program layanan multikultural secara terprogram, sistematis, terintegrasi, dan berkelanjutan, diharapkan. untuk dapat membantu mengembangkan kompetensi peserta didik secara optimal. Tujuan selanjutnya adalah untuk menganalisis implementasi konseling multikultural dengan pendekatan eklektik berdasarkan eksplorasi data potensi peserta didik. Bantuan yang diberikan oleh konselor didasarkan pada teknik-teknik Psychodynamic, Existential-Humanistic, Cognitive Behavioral Therapy, pendekatan Post-Modern.

Kata kunci: Konseling, Multikultural, Eklektik
\end{abstract}

Social, Humanities, and Education Studies (SHEs): Conference Series https://jurnal.uns.ac.id/shes

p-ISSN 2620-9284

e-ISSN 2620-9292 


\section{PENDAHULUAN}

Indonesia memiliki beragam budaya (Arifudin, 2007; Khoirina, Suyitno, \& Winarni, 2017; Soekarman \& Bariyyah, 2016). Setiap budaya memiliki karakteristik yang berbeda (Chatterjee, Pereira, \& Bates, 2018; Mostafazadeh, Narges, \& Azar, 2015; Sue \& Sue, 2016). Perbedaan karekteristik budaya menjadikan peserta didik yang berasal dari budaya berbeda mengalami kesulitan penyesuianan diri, kecemasan akademik, dan diskriminasi (Cormier, 2017; Kim, Oh, \& Mumbauer, 2019; Osborn, Venturo-Conerly, Wasil, Schleider, \& Weisz, 2019). Hal tersebut dikuatkan dengan keterangan peserta didik berbeda secara budaya yang memiliki keterampilan berbahasa kurang mengalami tekanan, dan perasaan rendah diri (Byeon, 2017). Hasil temuan lainnya menunjukan bahwa peserta didik berasal dari budaya yang berbeda mengalami hambatan bahasa, hambatan secara akademik, hambatan secara budaya dan perilaku rasisme (Nam \& Kim, 2019).

Potensi peserta didik berasal dari budaya berbeda tidak dapat berkembang secara maksimal, karena sebagian besar pendidik kurang memiliki kompetensi multikultural (Karatas \& Oral, 2015). Konselor yang memiliki kompetensi konseling multikultural rendah, konseli melaporkan tidak merasakan peningkatan kesejahteraan psikologis pada akhir sesi konseling (Dillon et al., 2016). Kompetensi konselor multikultural yaitu: (1) Kesadaran (self-awareness); (2) Sikap dan keyakinan (attitudes and beliefs); (3) Pengetahuan (knowledge); (4) Keterampilan (skills) dan (5) Aksi (action) (Kim et al., 2019; Riswanto, Mappiare-AT, \& Irtadji, 2017; Soekarman \& Bariyyah, 2016). Lebih lanjut, konselor multikultural diharapkan memiliki pemahaman tentang dirinya dan pemahaman terhadap peserta didik dengan budaya yang berbedabeda (Ratts, Singh, Nassar-Mcmillan, Butler, \& McCullough, 2016). Konselor multikultural dapat menghargai dan menghormati perbedaan budaya (Sofwan, Maman Rachman, 2016). Serta konselor multikultural diharapkan selalu mengembangkan kompetensi diri secara terus menerus (Zeleke, Karayiğit, \& Myers-Brooks, 2018).

Konseling multikultural adalah metode layanan yang diadaptasi dari keragaman budaya dalam masyarakat (Mostafazadeh et al., 2015). Konselor perlu untuk menyusun layanan berbasis multikultural secara terprogram (Pulliam, Paone, Malott, \& Shannon, 2019), sistematis (Rivas \& Hill, 2018), terintegrasi dan berkelanjutan (Banks, 2019; Nicolas, Byer, \& Ho, 2015). Tujuan dari konseling multikultural adalah membantu konseli untuk mengembangkan potensi dan menghubungkan internalisasi dengan realitas yang ada pada lingkungan (Bunu, 2016).

Konselor multikultural disarankan menggunakan pendekatan eklektik dalam pelayanan multikultural (Akhmadi, 2013; Sue \& Sue, 2016). Konseling eklektik adalah penggabungan berbagai pendekatan secara menyeluruh dan komprehensif (Arnout, 2019; Lazarus, 1967, 1989; Lazarus \& Beutler, 1992, 1993; Lebow, 2008). Lebih lanjut maksud pendapat tersebut yaitu, konselor merancang layanan konseling dengan memadukan berbagai teknik-teknik dari pendekatan konseling. Teknik-teknik yang digunakan merupakan teknik yang telah terbukti empiris dapat membantu mengembangkan potensi konseli (Lebow, 2008). Kami mengusulkan kepada konselor untuk mendapatkan data kebutuhan konseli dengan mengeksplorasi perasaan, kompetensi, semangat, kesempatan dan tujuan (Prayitno, 1998).

Eksplorasi perasaan memungkinkan peserta didik untuk mengungkapkan dan mengekspresikan perasaan yang dirasakannya (Paone, Malott, Pulliam, \& Gao, 2017). Eksplorasi kompetensi memungkinkan peserta didik untuk menumbuhkan wawasan, pengetahuan, ketrampilan, nilai dan sikap (Johnson \& Williams, 2015; Ratts et al., 2016). Eksplorasi semangat memungkinkan peserta didik menunjukkan perilaku tertarik atau tidak dalam proses konseling (Pulliam et al., 2019). Eksplorasi kesempatan memungkinkan peserta didik mengembangkan pendekatan pemecahan masalah dengan mengidentifikasi dunia nyata (Pietrantoni, Hennig, Totten, Shindelar, 
\& Keene-orton, 2019). Eksplorasi tujuan memungkinkan peserta didik untuk memahami diri lebih dalam, untuk mengidentifikasi tujuan aktual dirinya (Di Fabio \& Bernaud, 2018).

Dengan latar belakang yang telah dipaparkan, peneliti merumuskan masalah sebagai berikut. Bagaimana pelaksanaan konseling multikultural dengan pendekatan eklektik dapat mengoptimalkan potensi peserta didik? Bagaimana pelaksanaan eksplorasi perasaan, kompetensi, semangat, kesempatan dan tujuan dapat digunakan sebagai data untuk menyusun layanan konseling multikultural secara terprogram, sistematik, terintergasi, dan berkelanjutan? Tujuannya artikel ini yaitu, menganalisis pelaksanaan konseling multikultural dengan pendekatan eklektik untuk mengoptimalkan potensi peserta didik. Tujuan selanjutnya yaitu, menganalisis pelaksanaan eksplorasi perasaan, kompetensi, semangat, kesempatan dan tujuan digunakan untuk menyusun layanan konseling multukultural secara terprogram, sistematik, terintegrasi, dan berkelanjutan.

\section{PEMBAHASAN \\ Pelaksanaan Konseling Multikultural Mengunakan Pendekatan Eklektik}

Prosedur konseling eklektik diadaptasi oleh peneliti berdasarkan langkahlangkah pelaksanaan konseling dari berbagai pendekatan. Prosedur konseling sebagai berikut: (1) Tahap Pre-konseling; (2) Tahap pengantaran; (3) Tahap eksplorasi; (4) Tahap penafsiran; (5) Tahap pembinaan; (6) Tahap evaluasi dan tindak lanjut (Mulawarman, Nugraheni, Putri, \& Febrianti, 2019; Neukrug, 2012; Prayitno, 1998). Lebih lanjut akan dijabarkan sebagai berikut.

Tahap pra-konseling, tahap ini merupakan pertemuan awal antara konselor dan konseli (Gladding, 2015; Mulawarman et al., 2019). Kegiatan yang dilakukan pada tahap ini yaitu, melakukan identifikasi awal konseli, memberikan penjelasan dan persetujuan (informed counsent), menetapkan waktu konseling, membangun komitmen dan merupakan awal dari sebuah hubungan (Cormier, 2017; Gladding, 2015; Mulawarman et al., 2019; Neukrug, 2012).

Tahap pengantaran, tujuan utama tahap ini adalah membangun hubungan yang kuat dengan konseli dan mendefinisikan tujuan konseling (Neukrug, 2012). Membangun hubungan baik dilakukan dengan menerima kondisi konseli secara tulus, menciptakan kondisi yang fasilitatif dan kolaboratif serta memahami sudut pandang budaya konseli (Mulawarman et al., 2019; Neukrug, 2012). Pada tahap ini konselor perlu untuk menjelaskan proses konseling (Prayitno, 1998). Proses yang dimaksud yaitu, menjelaskan aturan, norma dan azas-azas konseling (Effendi, 2016).

Tahap eksplorasi, merupakan proses pencarian informasi berkaitan dengan potensi konseli (Corey, 2017; Effendi, 2016; Mulawarman et al., 2019; Neukrug, 2012). Konselor mengembangkan hubungan terapeutik dengan menyesuaikan gayanya agar sesuai dengan konseli, untuk memahami konseli secara budaya dan membawa perubahan dalam proses konseling (Sharf, 2012). Konselor dapat mengidentifikasi potensi konseli dengan mengesplorasi perasaan, kompetensi, semangat, kesempatan dan tujuan untuk memperoleh data potensi dari konseli.

Tahap penafsiran, tahap ini konselor menganalisis potensi peserta didik secara tepat dan sistematik (Sharf, 2012). Data analisis diperoleh dari proses eksplorasi. Konselor dapat mengunakan keterampilan interpretasi, untuk membantu konseli melihat potensi yang dapat dikembangkan (Effendi, 2016). Tujuan utama dari tahap ini yaitu, konselor menawarkan program bantuan pengembangan potensi secara terprogram, sistematik, terintegrasi dan berkelanjutan yang sesuai dengan potensi peserta didik. Program bantuan yang ditawarkan, mengacu pada teknik-teknik dari berbagai pendekatan yang telah terbukti secara empiris. 
Tahap pembinaan, tahap ini merupakan tahap konselor untuk melatih keterampilan yang dibutuhkan, membantu mengembangkan potensi, dan menyadarkan konseli terhadap situasi yang mendukung (Chan, Yeh, \& Krumboltz, 2015; Mulawarman, 2019; Mulawarman et al., 2019). Konselor menerapkan teknikteknik yang sudah didiskusikan dengan konseli pada tahap penafsiran. Teknik yang diterapkan misalnya, scaling, acting as if, empty chair, self-talk, role play (Erford, 2015).

Tahap evaluasi dan tindak lanjut, tahap ini bertujuan untuk menilai pelaksanaan konseling dan menentukan langkah selanjutnya dari proses konseling (Mulawarman, 2019; Mulawarman et al., 2019). Konselor mempertimbangkan palaksanaan konseling berlanjut ke sesi berikutnya atau berakhir (Neukrug, 2012). Hal yang perlu dipertimbangan antara lain, (1) Konseli telah memiliki kompetensi untuk menangani hambatan yang berulang di masa depan; (2) Konseli mampuan untuk mengembangkan potensi secara efektif, menikmati hidup, dan bahagia; (3) Konseli telah menunjukan pengurangan atau penghilangan tingkah laku bermasalah; (4) Pelaksanaan konseling telah mencapai titik maksimal (residu problem, yang tidak dapat terselesaikan dengan proses konseling) (Gladding, 2015; Mulawarman et al., 2019; Neukrug, 2012).

\section{Pelaksanaan Eksplorasi Potensi Konseli}

Mengesplorasi perasaan. Konselor dapat menanyakan beberapa hal. Misalnya, "Dapatkah anda menceritakan apa yang saat ini anda rasakan?" atau "Coba ceritakan! Apa yang anda rasakan saat ini?" dan dapat juga menyakatan "Menurut anda kondisi saat ini, jika dinilai mengunakan skala 1-10. Dimana 1 merupakan kondisi paling buruk dan 10 merupakan kondisi paling baik, nilainya berapa?" Untuk mendapatkan data lebih banyak, konselor dapat mengunakan keterampilan dasar konseli. Konselor dapat mengunakan keterampilan dan teknik-teknik konseling seperti keterampilan leading, reflecting, dan summarizing, scaling, problem free talk, dan spitting in the soup (Effendi, 2016; Erford, 2015).

Mengesplorasi kompetensi. Konselor dapat menanyakan "Coba ceritakan! Menurut pemahaman anda tentang ...... seperti apa? (untuk menanyakan wawasan)". Untuk mengesplorasi keterampilan, konselor dapat menanyakan "Coba ceritakan! Apa yang anda lakukan ketika hal itu terjadi?". Untuk mengesplorasi sikap, konselor dapat menanyakan "Coba ceritakan! Apa dampak dari ..... sehingga menggangu anda?". Konselor dapat mengunakan teknik konseling acting as if, confrontation, self-talk (Erford, 2015) untuk memperdalam dan mengeplorasi potensi konseli.

Mengidentifikasi semangat. Konselor dapat mengamati respon yang ditunjukan dari konseli. Respon yang diamati misalnya, "Apakah konseli tertarik membahas topik tersebut?", selanjutnya, "Seberapa besar usaha yang sudah dilakukan oleh konseli untuk dapat mengembangkan potensinya". Konselor dapat menggunakan keterampilan confrontasi, reflecting dan interpretation (Effendi, 2016) untuk mengidentifikasi semangat.

Mengesplorasi kesempatan. Konselor perlu mengesplorasi kesempatan jika, penghambat perkembangan potensi konseli dikarenakan sebab dari luar diri (Prayitno, 1998). Konselor dapat menanyakan "Menurut anda, kapan waktu yang tepat untuk menyatakan hal itu kepada ....?" atau "Pada kondisi seperti apa, waktu yang paling tepat untuk melakukan hal itu?". Konselor dapat menggunakan keterampilan dan teknik konseling seperti reflecting, interpretation, clarification, exception question, dan miracle question (Effendi, 2016; Erford, 2015; Mulawarman et al., 2019) untuk memperoleh informasi dari konseli.

Mengesplorasi tujuan. Ekplorasi tujuan penting untuk konselor sadar akan bias budaya, dan tidak mengarahkan konseli kepada tujuan yang tidak sesuai dengan 
keyakinan dan nilai yang dianut oleh konseli (Cormier, 2017). Konselor dapat menanyakan "Coba ceritakan! Apa yang anda inginkan?" atau "Coba sebutkan! Apa yang menjadi harapan anda?" Konselor dapat menggunakan keterampilan reflecting, interpretation dan summarizing (Effendi, 2016) untuk mengetahui apa yang menjadi harapan dari konseli.

\section{SIMPULAN}

Berdasarkan hasil penelitian pelaksanaan konseling eklektik terbukti efektif untuk mengembangkan kecerdasan spiritual (Arnout, 2019). Hasil penelitian lain konseling eklektik efektif untuk mengurangi gejala kecemasan, depresi dan gejala fisik di antara pasien diabetes (Shahrabad, Bayazi, Zafari, Teimouri, \& Rajabzadeh, 2018). Hasil penelitian lain mendukung pengunaan konseling eklektik untuk meningkatkan integritas psikologis dan mereduksi perilaku melukai diri sendiri (Keshavarz-Afshar, Nameni, Safarifard, \& Kheirabadi, 2019).

Berdasarkan hasil penelitian terdahulu. Pengunaan konseling eklektik secara empiris efektik karena, penggunaan dua atau lebih pendekatan konseling yang berbeda dengan konseli yang sama menjadi efektif (Arnout, 2019; Keshavarz-Afshar et al., 2019; Shahrabad et al., 2018). Hasil secara empiris mendukung pengunaan konseling eklektik untuk meningkatkan potensi dan kesejahteraan psikologis konseli.

Konseling multikultural dengan pendekatan eklektik dapat menjadi pertimbangan untuk dilakukan. Konseling ekletik berbasis bukti eksplorasi perasaan, kompetensi, semangat, kesempatan dan tujuan akan mempermudah konselor untuk penyusunan program. Program yang sesuai dengan potensi peserta didik beda secara budaya, dinilai lebih dibutuhkan (Cormier, 2017; Gökbulut, Yeniasır, \& Karabacak, 2019). Artikel ini merupakan kerangka teori pelaksanaan konseling multikultural dengan mengguanakan pendekatan ekletik. Rekomendasi penelitian selanjutnya, pelaksanaan konseling multikultural dengan pendekatan eklektik enam tahap perlu diuji secara empiris efektifitasnya. Pelaksanaan ekplorasi untuk memperoleh data potensi peserta didik perlu untuk diuji secara empiris efektifitasnya.

\section{DAFTAR PUSTAKA}

Akhmadi, A. (2013). Peningkatan Kesadaran Multikultural Konselor (Guru BK). Muaddib, 3(2), 18-36.

Arifudin, I. (2007). Urgensi Implementasi Pendidikan Multikultural di Sekolah. INSANIA: Jurnal Pemikiran Alternatif Kependidikan, 12(2), 220-233. https://doi.org/10.24090/insania.v12i2.252

Arnout, B. I. A. (2019). Effectiveness of Counseling Eclectic Program in Developing Spiritual Intelligence of University Students. 27(03), 16-28.

Banks, B. M. (2019). Meet Them Where They Are: An Outreach Model to Address University Counseling Center Disparities. Journal of College Student Psychotherapy, 00(00), 1-12. https://doi.org/10.1080/87568225.2019.1595805

Bunu, H. Y. (2016). the Implementation of Multicultural Approach in Guidance and Counseling in High Schools. Cakrawala Pendidikan, 35(3), 386-402. Retrieved from https://media.neliti.com/media/publications/87048-none9ca6b68f.pdf

Byeon, H. (2017). Chi-Square Automatic Interaction Detection Modeling for Predicting Depression in Multicultural Female Students. International Journal of Advanced Computer Science and Applications, 8(12), 179-183. https://doi.org/10.14569/ijacsa.2017.081222

Chan, A. W., Yeh, C. J., \& Krumboltz, J. D. (2015). Mentoring ethnic minority counseling and clinical psychology students: A multicultural, ecological, and relational model. Journal of Counseling Psychology, 62(4), 592-607. 
https://doi.org/10.1037/cou0000079

Chatterjee, A., Pereira, A., \& Bates, R. (2018). Impact of individual perception of organizational culture on the learning transfer environment. International Journal of Training and Development, 22(1), 15-33. https://doi.org/10.1111/ijtd.12116

Corey, G. (2017). Theory and Practice of Counseling and Psychotherapy Tenth Edition. Cengage Learning.

Cormier, S. (2017). Counseling Strategies And Interventions For Profesional Helpers (alih bahasa: Annisa Nuriowandari) (9th ed.). Person Education.

Di Fabio, A., \& Bernaud, J. L. (2018). Narrative Interventions in Post-modern Guidance and Career Counseling: A Review of Case Studies and Innovative Qualitative Approaches. Springer.

Dillon, F. R., Odera, L., Fons-Scheyd, A., Sheu, H. Bin, Ebersole, R. C., \& Spanierman, L. B. (2016). A dyadic study of multicultural counseling competence. Journal of Counseling Psychology, 63(1), 57-66. https://doi.org/10.1037/cou0000118

Effendi, K. (2016). Proses Dan Keterampilan Konseling. Pustaka Pelajar.

Erford, B. T. (2015). Second Edition 40 Techniques Every Counselor Should Know. Pearson Education.

Gladding, S. T. (2015). Konseling: Profesi yang Menyeluruh (alih bahasa: P.M. Winarno) (Enam). PT Indeks.

Gökbulut, B., Yeniasır, M., \& Karabacak, H. E. (2019). Opinions and expectations of turkish and foreign national students studying at northern Cyprus universities concerning multicultural and inclusive/integrated education settings. Education Sciences, 9(1), 1-12. https://doi.org/10.3390/educsci9010009

Johnson, A., \& Williams, D. J. (2015). White racial identity, color-blind racial attitudes, and multicultural counseling competence. Cultural Diversity and Ethnic Minority Psychology, 21(3), 440-449. https://doi.org/10.1037/a0037533

Karatas, K., \& Oral, B. (2015). Teachers' Perceptions on Culturally Responsiveness in Education. Journal of Ethnic and Cultural Studies Copyright, 2(2), 47-57.

Keshavarz-Afshar, H., Nameni, E., Safarifard, R., \& Kheirabadi, R. (2019). The Effectiveness of Lazarus Multimodal Training on Responsibility ,. 13(2), 7378.

Khoirina, I., Suyitno, S., \& Winarni, R. (2017). PENGENALAN BUDAYA INDONESIA MELALUI NOVEL RANAH 3 WARNA KARYA A. FUADI UNTUK PEMBELAJAR BIPA. Proceedings Education and Language International Conference, 1(1).

Kim, N., Oh, S., \& Mumbauer, J. (2019). Supporting International Students: Enhancing College Counselors' Multicultural Counseling Competence. Journal of College Counseling, 22(2), 179-192. https://doi.org/10.1002/jocc.12129

Lazarus, A. A. (1967). In support of technical eclecticism. Psychological Reports, 21(2), 415-416. https://doi.org/10.2466/pr0.1967.21.2.415

Lazarus, A. A. (1989). Why I am an Eclectic (Not an Integrationist). British Journal of Guidance \& Counselling, 248-258. https://doi.org/10.1080/03069888908260037

Lazarus, A. A., \& Beutler, L. E. (1992). The Future Of Technical Eclecticim. Psychotherapy, 29(1), 11-20.

Lazarus, A. A., \& Beutler, L. E. (1993). On Technical Eclecticism. Journal of Counseling \& Development, 71, 381-385. https://doi.org/10.1002/j.15566676.1993.tb02652.x

Lebow, J. L. (2008). Twenty-First Century Psychotherapies: Contemporary Approaches to Theory and Practice. Retrieved from https://books.google.com/books?id=YT50xokDC1UC\&pgis=1 
Mostafazadeh, E., Narges, K., \& Azar, G. (2015). Analysis of Multi-Cultural Education Concept in Order to Explain Its Components. Journal of Education and Practice, 6(1), 1-13.

Mulawarman. (2019). SFBC (Solution-Focused Brief Counseling), Konseling Singkat Berfokus Solusi: Konsep, Riset, dan Prosedur. Prenadamedia Group.

Mulawarman, Nugraheni, E. P., Putri, A., \& Febrianti, T. (2019). Psikologi Konseling Sebuah Pengantar Bagi Konselor Pendidikan. Prenadamedia Group.

Nam, J. K., \& Kim, D. (2019). Conceptualizing Multicultural Counseling Competence for International Students in Korea: A Focus on University Counseling Centers and Counselors 국내 외국인 유학생을 위한. Seoul National University.

Neukrug, E. (2012). Edward S. Neukrug The World of the Counselor An Introduction to the Counseling Profession, 4th Edition. Nelson Education.

Nicolas, G., Byer, K., \& Ho, K. (2015). Implementing culturally sensitive and sustainable mental health training programs internationally: lessons from Haiti. International Journal of Culture and Mental Health, 8(4), 446-457. https://doi.org/10.1080/17542863.2014.996237

Osborn, T. L., Venturo-Conerly, K., Wasil, A., Schleider, J. L., \& Weisz, J. (2019). Depression and anxiety symptoms, social support, and demographic factors among Kenyan high school students. Journal of Child and Family Studies. https://doi.org/10.1007/s10826-019-01646-8

Paone, T. R., Malott, K. M., Pulliam, N., \& Gao, J. (2017). Use of Photovoice in Processing Race-Based Topics in a Multicultural Counseling Course. Journal of Creativity in Mental Health, 1-14. https://doi.org/10.1080/15401383.2017.1294517

Pietrantoni, Z., Hennig, J., Totten, J., Shindelar, L., \& Keene-orton, B. (2019). GameBased Learning in Counselor Education: Strategies for Counselor Training Game-Based Learning in Counselor Education: Strategies for Counselor. 12(2).

Prayitno. (1998). Konseling Pancawaskita Kerangka Konseling Eklektik. Padang: Fakultas IImu Pendidikan IKIP Padang.

Pulliam, N., Paone, T. R., Malott, K. M., \& Shannon, J. (2019). The Experiences of Students of Color at a Predominantly White Institution: Implications for Counselor Training. Journal of Multicultural Counseling and Development, 47(4), 239-255. https://doi.org/10.1002/jmcd.12156

Ratts, M. J., Singh, A. A., Nassar-Mcmillan, S., Butler, S. K., \& McCullough, J. R. (2016). Multicultural and Social Justice Counseling Competencies: Guidelines for the Counseling Profession. Journal of Multicultural Counseling and Development, 44(1), 28-48. https://doi.org/10.1002/jmcd.12035

Riswanto, D., Mappiare-AT, A., \& Irtadji, M. (2017). Kompetensi Multikultural Konselor pada Kebudayaan Suku Dayak Kalimantan Tengah. JOMSIGN: Journal of Multicultural Studies in Guidance and Counseling, 1(2), 215. https://doi.org/10.17509/jomsign.v1i2.8320

Rivas, M., \& Hill, N. R. (2018). Counselor Trainees' Experiences Counseling Disability: A Phenomenological Study. Counselor Education and Supervision, 57(2), 116-131. https://doi.org/10.1002/ceas.12097

Shahrabad, H. D., Bayazi, M. H., Zafari, Z., Teimouri, S., \& Rajabzadeh, F. (2018). The effect of Lazarus multimodal therapy on depression, anxiety, and blood glucose control in women with type 2 diabetes. Journal of Fundamentals of Mental Health, 20(4), 302-309.

Sharf, R. S. (2012). Theories of Psychotherapy and Counseling: Concepts and Cases, 5th Edition. Belmont: Brooks/Cole. 
4th National Seminar on Guidance and Counseling (SNBK 2019) and Workshop on

Pedagogical Theory and Practice (WTPP 2019)

SHEs: Conference Series 2 (2) (2019) 56 - 63

Soekarman, F. ., \& Bariyyah, K. (2016). Students multicultural awareness. COUNSEDU/ The International Journal of Counseling and Education, 1(1), 16. https://doi.org/10.23916/16-21.0016.11-i30b

Sofwan, Maman Rachman, S. (2016). The Journal of Educational Development MULTICULTURALISM-BASED SCOUTING EDUCATION IN JUNIOR. 4(1), 24-30.

Sue, D. W., \& Sue, D. (2016). Counseling the culturally diverse: theory and practice / Derald Wing Sue, David Sue. - 7th edition. https://doi.org/10.1017/CBO9781107415324.004

Zeleke, W. A., Karayiğit, C., \& Myers-Brooks, K. (2018). Using Self-Regulated Learning Strategies to Develop Students' Multicultural Counseling Competency. Journal of Multicultural Counseling and Development, 46(1), 40-57. https://doi.org/10.1002/jmcd.12091 